\title{
Solar radiation exposure of shielded air temperature sensors and measurement error evaluation in an urban environment: a preliminary study in Florence, Italy
}

\author{
M. Petralli ${ }^{1}$, L. Massetti ${ }^{2}$, and S. Orlandini ${ }^{1}$ \\ ${ }^{1}$ Interdepartmental Centre of Bioclimatology, University of Florence, Italy \\ ${ }^{2}$ Institute of Biometeorology, National Research Council, Florence, Italy
}

Received: 30 December 2008 - Revised: 12 January 2009 - Accepted: 17 January 2009 - Published: 1 April 2009

\begin{abstract}
Particularly in summer, thermal conditions in urban areas are influenced by solar radiation and human health can be strongly affected by the higher temperature regime increased by the Urban Heat Island effect (UHI). Many studies have been carried out to estimate the temperature distribution in urban areas and some of these use or are based on data collected by meteorological instruments placed within the cities. At microscale, temperature collected by sensors can be influenced by the underlying surface characteristics and the closeness to warm surfaces. The aim of this study is to investigate how different exposure to solar radiation can affect air temperature measurement in streets and gardens. The study was carried out on two different areas in Florence during summer 2007. Shielded air temperature sensors were placed in a street of a high density built-up area and in a green area. Each area was monitored by two sensors, sited in different solar radiation exposure: one in a sunny area and the other in a shaded one. A preliminary data analysis showed a difference in every site between the air temperature values collected by the two sensors especially from the morning to the afternoon. The relationship between air temperature differences and synoptic meteorological conditions were also analyzed. In conclusion, the solar radiation exposure of a monitoring station is an important parameter that must be considered both during the instruments siting and the analysis of data collected by sensors previously placed. The result of this study shows that during particular synoptic conditions, data collected by the two sensors of the same area can be different.
\end{abstract}

\section{Introduction}

In Italy, the rise in air temperature values as a consequence of Global Warming and Climate Change is very important: in fact, during Summer the higher values of air temperature can have some important consequences in terms of human health (Conti et al., 2005) especially in urban areas for the Urban Heat Island effect (Beuchley et al., 1972). Air temperature is the most important variable studied in biometeorology, in fact in the literature it is easy to find many studies on the relationship between air temperature and human health (Ballaster et al., 1997; Morabito et al., 2005), and in Florence it was found that during Summer the number of Emergency Calls (Petralli et al., 2005) and of hospital admission of Florence citizens and also of tourists rises on days with higher

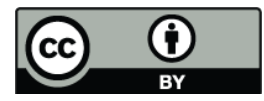

Correspondence to: M. Petralli (martina.petralli@unifi.it) values of air temperature (Morabito et al., 2004). Air temperature distribution within a city is often studied using a network of air temperature instruments. The aim of this study is to investigate how different exposure to solar radiation can affect air temperature measurement in streets and gardens.

\section{Materials and method}

This study was made in Florence, a very important city for history and tourism, located in the centre of Italy. The climate is continental, with dry summer and winter and rainy spring and autumn. The study was carried out on two different areas of Florence: air temperature sensors $\left(\mathrm{HOBO}^{\circledR}\right.$ PRO series Temp/RH Data Logger) with solar radiation shields (RS1-HOBO ${ }^{\circledR}$ PRO accessories) were placed in a street with high density of buildings and in an urban park located near the first placement (the distance was about $1 \mathrm{~km}$ ). In each study area, two air temperature sensors were placed at the standard height of $2 \mathrm{~m}$ above ground level (Egan and 
Table 1. Maximum and minimum air temperature values collected in the street and in the park from sensors placed in the shaded and in the sunny area.

\begin{tabular}{lccccccccc}
\hline & \multicolumn{4}{c}{ Park } & \multicolumn{3}{c}{ Street } \\
\hline & \multicolumn{2}{c}{$T_{\min }$} & \multicolumn{2}{c}{$T_{\max }$} & \multicolumn{2}{c}{$T_{\min }$} & \multicolumn{2}{c}{$T_{\max }$} \\
\hline & sun & shade & sun & shade & sun & shade & sun & shade \\
\hline Maximum & 19.5 & 19.3 & 38.3 & 37.3 & 20.0 & 20.0 & 38.6 & 37.7 \\
Mean & 16.8 & 17.0 & 28.2 & 28.1 & 17.8 & 17.6 & 29.9 & 29.6 \\
Minimum & 12.7 & 13.1 & 21.5 & 21.9 & 14.0 & 14.0 & 23.1 & 23.1 \\
\hline
\end{tabular}

Baldelli, 2008): one in a sunny area and the other in a shaded one. In both cases (street and park) the distance between the sensors was about $60 \mathrm{~m}$. The temperature gradient in an urban environment could be very large even in a so little distance, but this is not the case because in the park surfaces were more thermally homogeneous and in the street both sensors were placed in the same parking lot, with the same type of surfaces and distance from the buildings on the surroundings. Hourly data were collected by each sensor and were analyzed firstly to calculate daily maximum, minimum and average temperature and then to see the hourly differences between the stations. Air temperature differences between the two stations were analyzed with the compare mean test. The relationship between air temperature differences and synoptic meteorological conditions (solar radiation and wind speed) were also analyzed with the $\mathrm{P}$ product correlation using SPSS 11.5 (Statistical Package for Social Sciences, (C) SPSS Inc., USA).

\section{Results}

As a first data analysis, the differences between the daily maximum, minimum and average values of the sunny and the shaded sensors of each area were compared. In the whole Summer period, the minimum air temperature values varied between 12.7 and $21.9^{\circ} \mathrm{C}$ in the park and between 14.0 and $23.1^{\circ} \mathrm{C}$ in the street. The average air temperature varied between 16.8 and $28.2^{\circ} \mathrm{C}$ in the park and 17.6 and $29.9^{\circ} \mathrm{C}$ in the street and maximum air temperature varied between 19.3 and $38.3^{\circ} \mathrm{C}$ in the urban park and between 20 to $38.6^{\circ} \mathrm{C}$ in the built up area (Table 1). The differences between data collected in the sunny area or in the shaded one were approximately the same for minimum and average air temperature in both areas while maximum air temperature values in the sunny area were higher both in the street (Fig. 1a) and in the park (Fig. 1b). The average difference in maximum air temperature was about $1^{\circ} \mathrm{C}$ and, in some days, it reached values of $1.6^{\circ} \mathrm{C}$.

The hourly trend of a typical sunny day in Florence was then analyzed (Fig. 2a). The hourly trend was different in
Table 2. $P$ product correlation between solar radiation and wind speed on differences of air temperature in sunny and shaded areas in the street and in the park. Significance level: ${ }^{*} p<0.05,{ }^{* *} p<0.01$, ${ }^{* * *} p<0.001$.

\begin{tabular}{cllll}
\hline \multicolumn{3}{c}{ Street } & \multicolumn{2}{c}{ Park } \\
\hline hour & Solar radiation & Wind & Solar radiation & Wind \\
\hline 8 & $0.72^{* * *}$ & -0.33 & $0.73^{* * *}$ & -0.20 \\
9 & $0.67^{* * *}$ & $-0.46^{* * *}$ & $0.64^{* * *}$ & $-0.37^{* * *}$ \\
10 & $0.65^{* * *}$ & $-0.26^{*}$ & $0.66^{* * *}$ & $-0.32^{* *}$ \\
11 & $0.61^{* * *}$ & $-0.24^{*}$ & $0.70^{* * *}$ & $-0.40^{* * *}$ \\
12 & $0.49^{* * *}$ & -0.18 & $0.78^{* * *}$ & $-0.36^{* *}$ \\
13 & $0.43^{* * *}$ & -0.04 & $0.74^{* * *}$ & $-0.30^{* *}$ \\
14 & $0.26^{*}$ & -0.14 & $0.78^{* * *}$ & $-0.32^{* *}$ \\
15 & 0.16 & -0.14 & $0.70^{* * *}$ & -0.10 \\
\hline
\end{tabular}

Table 3. $P$ product correlation between hourly air temperature collected in the sunny sensor and differences of air temperature values between data collected in sunny and shaded areas. Significance level: ${ }^{*} p<0.05,{ }^{* *} p<0.01,{ }^{* * *} p<0.001$.

\begin{tabular}{cll}
\hline hour & Street & Park \\
\hline 8 & $0.25^{*}$ & $0.54^{* * *}$ \\
9 & $0.43^{* * *}$ & $0.62^{* * *}$ \\
10 & $0.48^{* * *}$ & $0.69^{* * *}$ \\
11 & $0.58^{* * *}$ & $0.72^{* * *}$ \\
12 & $0.48^{* * *}$ & $0.78^{* * *}$ \\
13 & $0.49^{* * *}$ & $0.77^{* * *}$ \\
14 & $0.40^{* * *}$ & $0.78^{* * *}$ \\
15 & $0.42^{* * *}$ & $0.71^{* * *}$ \\
\hline
\end{tabular}

the sunny and in the shaded sensors, in fact between 6 (that is near the sunrise) to 17 , the sunny sensor registered higher values than the shaded sensors. The mean hourly difference of air temperature between sun and shade of the whole period was also analyzed, taking into account the threshold of the accuracy of the sensors used (for the Hobo Pro is $0.2^{\circ} \mathrm{C}$ ). As data were collected by two different sensors, the threshold of the error must be added and reached $0.4^{\circ} \mathrm{C}$. The difference between the air temperature values collected by the two sensors were higher than the threshold of the error from 8 to 15 (Fig. 2b). This was also validated by the compare mean test that confirmed that the difference in those hours was significantly different from 0 (data not shown).

The correlation values between the weather variables and the differences collected in the built up area and in the urban park are shown in Table 2: significant differences of air temperature between sun and shade were then correlated to solar radiation and wind speed. The higher correlations were between the air temperature difference and solar radiation both 

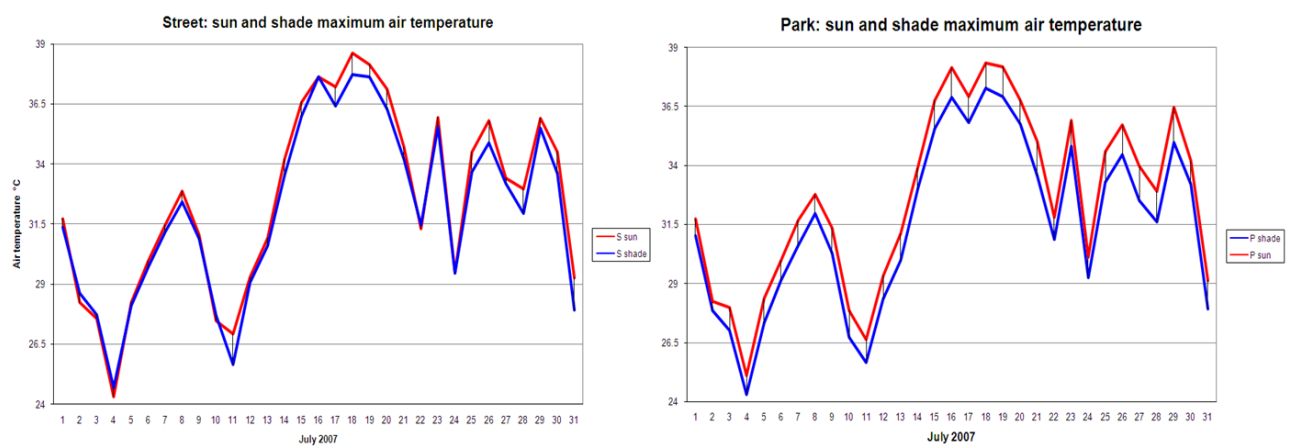

Figure 1. Differences between maximum air temperature in July 2007 of sensors placed in the street (a) and sensors placed in the urban park (b).
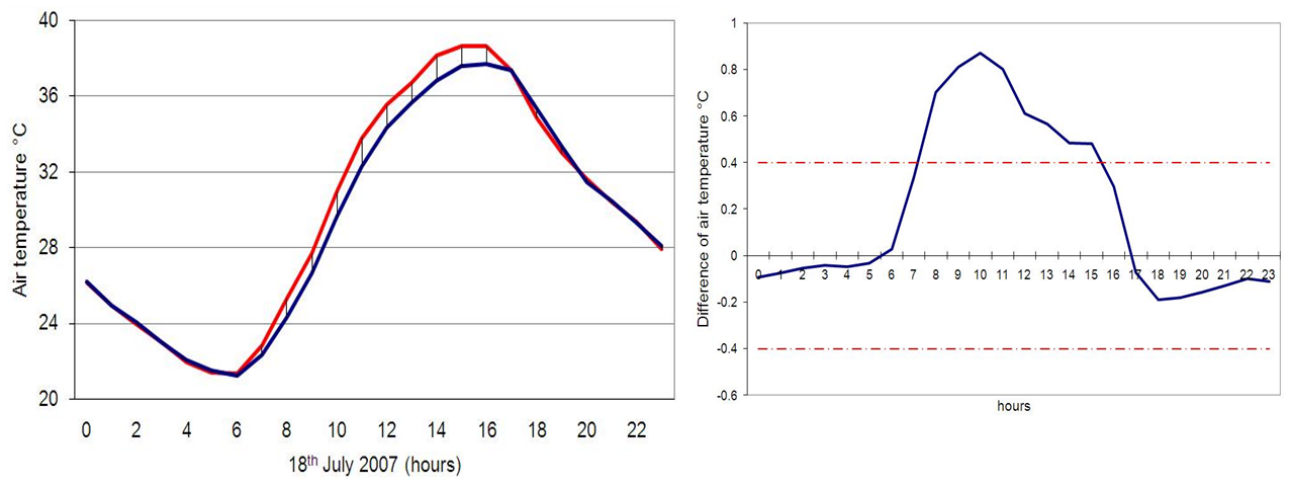

Figure 2. Mean hourly trend of air temperature in shade (blu line) and sun (red line) in a typical sunny day in Florence (a) and .mean hourly difference of air temperature between sun and shade (b).

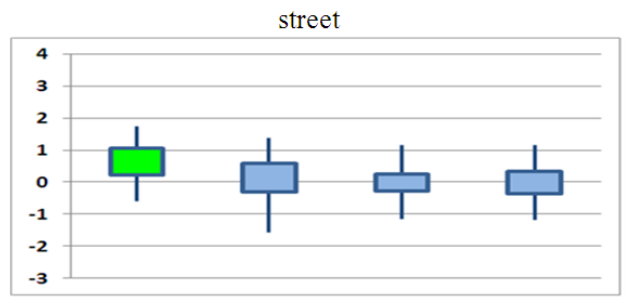

(a) (b) (c) (d)

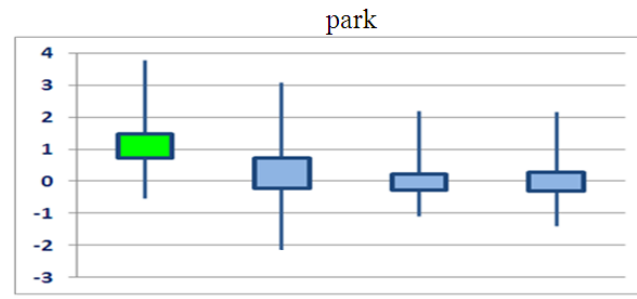

(e) (f) (g)

(h)

Figure 3. Box plot of the hourly difference between air temperature collected in sunny and shaded area in street (a-d) and park (e-h): difference without correction (a and e); difference after the application of linear regression correction on air temperature sunny values according to wind ( $\mathrm{b}$ and $\mathrm{f}$ ) solar radiation ( $\mathrm{c}$ and $\mathrm{g}$ ) and hourly air temperature ( $\mathrm{d}$ and $\mathrm{h}$ ). Boxes represent inter-quartile distance; whiskers, extreme values.

in the urban area and in the park. As expected, the correlation with the wind speed was negative, as with increasing wind speed the differences between air temperature values collected by the two sensors decreased. The correlation with the wind speed is significant only in few cases and, in any case, with lower values than solar radiation.

Linear regression was then applied to estimate the hourly difference in temperature between the stations using hourly values of solar radiation, mean wind speed and temperature. The relationship between the air temperature difference in sun and shade and the air temperature value of the sunny station was finally tested (Table 3): the correlation is statistically significant, but with lower values than solar radiation during the morning hours, while it has a higher significance after 13, especially in the built-up area.

The linear regression correction was then applied to the sunny data and the differences with the shaded values were then calculated (Fig. 3). The wind model is the worst and the solar radiation is the best both in street and park. 


\section{Conclusions}

The solar radiation exposure of a shielded naturally ventilated air temperature sensor is a very important parameter that must be considered both during the siting of the instruments and the analysis of data collected by sensors previously placed. The hourly difference between data collected in the same area by sensors placed in a sunny area or in a shaded one can reach $1.6^{\circ} \mathrm{C}$, both in a built up area and in an urban park and this difference is higher than the accuracy of the instrument from the Sunrise to 15 . With regard to daily values, the difference between maximum air temperatures was higher than the accuracy of the instrument, but the correlation was too weak to apply a correction.

Edited by: S. Szalai

Reviewed by: two anonymous referees

\section{References}

Conti, S., Meli, P., Minelli, P., Solimini, R., Toccaceli, V., Vichi, M., Beltrano, C., and Perini, L.: Epidemiologic study of mortality during the Summer 2003 heat wave in Italy, Env. Res., 98, 390399, 2005.

Ballaster, F., Corella, D., Pérez-Hoyos, S., Sáez, M., and Hervás, A.: Mortality as a function of temperature. A study in Valencia, spain, 1991-1993, Int. J. Epidemiol., 26(3), 551-561, 1997.

Beuchley, R. W., Van Bruggen, J., and Truppi, L. E.: Heath Island equals to Death Island?, Environ. Res., 5, 85-92, 1972.

Egan, K. and Baldelli, S.: Guidelines for Meteorological Station Reconnaissance And Meteorological Sensor Height Measurements, Center for Operational Oceanographic Products and Services, National Ocean Service, 2008.

Morabito, M., Crisci, A., Barcaioli, G., and Maracchi, G.: Climate Change: The Impact On Tourism Comfort At Three Italian Tourist Sites, in: Advances In Tourism Climatology, edited by: Matzarakis, A., De Freitas, C. R., and Scott, D., Ber. Meteor. Inst. Univ. Freiburg, Nr. 12, 56-65, 2004.

Morabito, M., Modesti, P. A., Cecchi, L., Crisci, A., Orlandini, S., Maracchi, G., and Gensini, G. F.: Relationship between wether and myocardial infarction: a biometeorological approach, Int. J. Cardiol., 105, 288-293, 2005.

Petralli, M., Morabito, M., Cecchi, L., Torrigiani, T., Bartolini, G., Orlandini, S.: Relationship between emergency calls and hot days in summer 2005 (Florence - Italy), Proceedings of the Sixth International Conference on Urban Climate, Goteborg (Sweden), 230-233, 2006. 